\title{
Isolation and Identification of Fungi Associated with the Spoilage of Sweet Orange (Citrus Sinensis) Fruits In Sokoto State
}

\author{
${ }^{* 1}$ I.Y. Tafinta, ${ }^{1}$ K.Shehu, ${ }^{1} \mathrm{H}$. Abdulganiyyu, ${ }^{1}$ A.M. Rabe and ${ }^{2}$ A. Usman \\ ${ }^{1}$ Department of Biological sciences, Usmanu Danfodiyo University, PMB 2346, Sokoto, Nigeria. ${ }^{5}$ Department of \\ Microbiology, Usmanu Danfodiyo University, PMB 2346, Sokoto, Nigeria. \\ [Corresponding Author, Email: iytafinta08@yahoo.com; 矛: +234(0)8065416393]
}

\begin{abstract}
This study was carried out in Sokoto Metropolis to isolate and identify fungi associated with the deterioration of sweet orange fruits. A total of one hundred samples of fresh sweet Oranges (Citrus sinensis $\mathrm{L}$ ) were used. First, a total of seventy samples were obtained from the three selected marketing centres in Sokoto metropolis (Central market, Kasuwar daji and Old market respectively), and transported immediately to mycology laboratory Usmanu Danfodio University, Sokoto for analysis. The oranges were kept under room temperature and observed after two weeks for spoilage. Each of the orange was cut and the liquid content inoculated on potato Dextrose Agar and incubated at ${ }^{\circ} 5^{\circ} \mathrm{C}$ and observed for $3-28$ days after which the different colonies obtained were identified using the slide culture technique. The fungal analysis shows that Apergillus fumigatus, Apergillus niger, Aspergillus flavus and Rhizopus stolonifer are associated with the spoilt sweet orange fruit (Citrus sinensis) with frequencies of occurrence of 22\%, $17 \%, 25 \% 36 \%$ respectively. Fresh sweet orange fruits (thirty samples: ten each from the three markets respectively) were obtained, and the isolated culture for each of the identified fungi specie inoculated on each of the freshly purchased oranges and incubated to check for their spoilage ability. The result shows that $R$. stolonifer and $A$. flavus were the most active with rots diameter of $45 \mathrm{~mm}$ and $35 \mathrm{~mm}$, respectively. And the least active fungus was $A$. niger having a rots diameter of $25 \mathrm{~mm}$.
\end{abstract}

Keywords: Fungal analysis, pathogenic, frequency of occurrence, Citrus sinensis.

\section{INTRODUCTION}

Citrus sinensis (L.), family Rutaceae, is one of the major commercial fruit crops that are widely consumed both as fresh fruit or juice due to its high vitamin C content and antioxidant potential (Gorinstein et'al., 2001). The crop is mainly cultivated in the tropical and subtropical regions of the world in over 137 countries on six continents (Ismail and Zhang, 2004). Brazil is the largest producer followed by the United State of America (USA), China and Mexico. Spain, USA and South Africa are the largest exporting countries followed by Turkey and Morocco (Citrus Commodity Notes, 2005). Sweet orange is an important fruit crop in international trade next to grapes requiring excellent quality and shelf life attributes. Unfortunately, it is known to be attacked by several pathogens that affect the fruit quality. In developing countries, where protection and proper handling of fresh fruit is an adequate, losses during transit and storage can represent an excess of $50 \%$ of the harvested crop (Eckert and Ogawa, 1985).

Spoilage microorganisms can be introduced into the crop on the seed itself, during crop growth in the field, during harvesting and postharvest handling, or during storage and distribution (Barth et al., 2009). Most citrus fruits are, in association with a variety of bacteria, and fungi, but due to a particular environmental condition, only a small proportion of the kind of microorganism(s) present will be able to grow rapidly and cause its deterioration (Alfred and Patrick, 1985). Postharvest losses and decay of Citrus fruits can be traced to infections that occur either between flowering and fruit maturity or during harvesting and subsequent handling and storage activities. Pre-harvest infections are mainly caused by fungal pathogens such as Phytophthora spp, Colletotrichum glocosporiodes (Browning et al., 1995: El Ghaouth et al., 2002). Isolation and identification of the pathogens are desirable in order to strategize the control measures with a view to reducing losses due to spoilage or infections (Singleton et al., 1992). Occasionally, a disease is caused by new, previously unknown pathogens that must be isolated and studied. If the identity of the pathogen is suspected or determined and a specific nutrient medium that allows only the growth of that pathogen is available, then the isolation of the particular pathogen is achieved by growing a small section of infected tissue on such media (Tsao, 1970). Ifeanyi (1995), states that fungi such as yeast and mould are mainly associated with the diseased and deteriorated citrus fruits.

Apart from mycotoxin contamination of orange fruits, the presence of fungi eventually leads to disease development in the field when the infected seeds in the fruits are planted. The objective of this study was 
to isolate and identify fungi associated with postharvest deterioration of sweet orange fruits in Sokoto metropolis, Nigeria.

\section{MATERIAL AND METHODS Samples Collection}

A total of seventy (70) sweet orange fruits (Citrus sinensis) were obtained from three different markets in Sokoto metropolis and thirty healthy orange fruits were later obtained for the pathogenecity test after the isolation of the fungi. All the samples collected were placed in a sterile polythene bags separately and labelled appropriately and transported to Mycology laboratory, Department of Biological Sciences, Usmanu Danfodiyo University, Sokoto for the fungal analysis.

\section{Isolation of Fungi}

The infected citrus fruits were surface sterilized with cotton wool soaked in $70 \%$ alcohol. The fruits were then cut out into small segments (3mm diameter) using sterilized scalpel, the segments of the infected fruits were then plated on solidified Potato Dextrose Agar plates(90mm diameter) aseptically. Inoculated plates were incubated at $28 \pm 3^{\circ} \mathrm{C}$ for 7 days.

From the incubated plates the different fungal isolates with different colorations observed includes; (i) Brown (ii) Black (iii) Green and (iv) White which signified the occurrence of different fungal colonies. The fungal colonies that emerged were continuously sub-cultured in order to obtain a pure culture of the fungal isolates.

\section{Identification of the Fungal Isolates}

The one to four weeks pure cultures of the fungal isolates were identified using cultural and morphological features such as colony growth pattern, conidial morphology and pigmentation (Sparrow, 1976), by slide culture techniques (Oyeleke and Manga, 2008). A small portion of the aerial mycelia from the representative culture was picked using a sterile inoculating needle and inoculated on a slide containing a fraction of a prepared solidified Potato Dextrose agar and incubated for 24-48hours, after which it was viewed under the light microscope first with $(x 10)$ and then with (x40) objective lens to detect spore, hyphae and other special structures.

The Morphological characteristics and appearance of the fungal isolated from the rotten Citrus sinensis fruits used in this study were confirmed and authenticated with the help of Mycological Atlas of Robert and Ellen (1988).

\section{Pathogenecity Test}

Pathogenecity or decay test was carried out in order to know if the isolated fungi were really responsible for the spoilage of citrus fruits. Healthy fruits were surface sterilized with $75 \%$ alcohol. Cylindrical plug tissues were cut out from the fruits using a sterilized $2 \mathrm{~mm}$ sized cork borer. Agar disc containing oneweek old fungal culture were aseptically placed in these holes, then covered and sealed off by means of petroleum jelly. The procedure was repeated separately across each of the fungal isolates. The inoculated samples and the control were placed in sterile polythene bags and incubated at $28 \pm 3^{\circ} \mathrm{C}$ for 14 days. The point of inoculation of each type of fungus was examined and recorded. The diameter of the rotten portion of the orange fruits was measured. The fungi were later re-isolated from the inoculated fruits and compared with the initial isolates.

\section{RESULTS AND DISCUSSION}

The isolated fungi from the rotten of the Citrus sinensis fruit and their frequencies of occurrence are shown in Table 1. The pathogenicity of the isolated fungi from the rotten Citrus sinensis fruit after fourteen days of incubation shown in Table 2.

Table 1: Fungi isolated from rotten of Citrus sinensis Fruits in Sokoto, Nigeria.

\begin{tabular}{lc}
\hline Fungal Isolates & Frequency (\%) \\
\hline Rhizopus stolonifer & 36.0 \\
Aspergillus flavus & 25.0 \\
Aspergillus fumigatus & 22.0 \\
Aspergillus niger & 17.0 \\
\hline
\end{tabular}

Table 2: Decay rate of Fungi isolated from rotten Citrus sinensis fruits after 14 days of incubation

\begin{tabular}{lc}
\hline Fungal Isolates & Diameter of Rot $(\mathrm{mm})$ \\
\hline Rhizopus stolonifer & 45.0 \\
Aspergillus flavus & 35.0 \\
Aspergillus fumigatus & 30.0 \\
Aspergillus niger & 25.0 \\
\hline
\end{tabular}

This study shows that $A$. fumigatus, $A$. niger, $A$. flavus and $R$. stolonifer and some yeasts were found in the spoilt sweet orange fruits sold in Sokoto State, Nigeria. Some of these pathogens have been reportedly isolated from Pawpaw fruits in Nigeria (Baiyewu et al., 2007; Chukwuka et al., 2010). Out of the fungi isolated, $R$. stolonifer has the highest frequency of occurrence (36\%) followed by $A$. flavus (25\%) then $A$. fumigatus (22\%) and $A$. niger with 17 $\%$ frequency of occurrence. This is however in agreement with Ifeanyi, (1995) and Bello ( 2010) 
whom both isolated about seven different fungal genera from different fruits including sweet orange fruits and When these isolates were aseptically inoculated into healthy susceptible fruits, the characteristic symptoms originally observed were also noticed. All the four organisms were successfully taking part in the decay and are thus confirmed as the causal organism of fruit decay (Baiyewu et al., 2007; Chukwuka et al., 2010). Thus These fungi were also found to be associated with the deterioration of orange fruits, All the four organisms isolated were confirmed to cause spoilage on the sweet orange fruits but in varying degrees. Of all the isolated fungi, $R$. stolonifer and $A$. flavus were the most pathogenic with rapid disintegration of the treated fruits in 14days having a rots diameter of $45 \mathrm{~mm}$ and $35 \mathrm{~mm}$, respectively. And the least pathogenic fungus was $A$. niger having a rots diameter of $25 \mathrm{~mm}$.

Generally, fungi that cause spoilage are considered toxigenic or pathogenic (Al-Hindi et al., 2011). Some moulds may produce mycotoxins (Tournas and Stack, 2001). The fungi isolated in this study have been reported to produce secondary metabolites in plants tissues. These secondary metabolites are potentially harmful to humans and animals (Eaton and Groopman, 1994; Baiyewu et al., 2007). A good example is Aflatoxin which has been implicated in cancer of the liver (heplatoma), aflatoxicosis and also acute hepatitis in humans, especially in the developing world (Krogh, 1992; Prasad, 1992; Eaton and Groopman, 1994; Muhammad et al., 2004; Baiyewu et'al., 2007). Pathogenic fungi, on the other hand, could cause infections or allergies (Monso, 2004).

\section{CONCLUSION}

In this study, it was found that $A$. fumigatus, $A$. niger, $A$. flavus and $R$. stolonifer are detected in spoilt sweet oranges. Therefore, sweet orange fruits should be properly refrigerated and should be discarded of there are any changes notice in the colour or taste of the fruit as will be hazardous to human health.

\section{REFERENCES}

Alfred, I. and Patrick, O. (1985). Food values of some tropical fruits and vegetables in integral food science and technology for tropics, $2^{\text {nd }}$ edition Pp.305-306.

Baiyewu, R.A., Amusa, N.A., Ayoola, O.A. and Babalola, 0.0. (2007). Survey of the postharvest diseases and aflatoxin contamination of marketed Pawpaw fruit (Carica papaya L.) in South Western Nigeria.
African Journal of Agricultural Research, 2(4): 178-181.

Barth, M., Hankinson, T.R., Zhuang, H. and Breidt, F. (2009). Microbiological Spoilage of Fruits and Vegetables. W.H. Sperber, M.P. Doyle (eds.), Compendium of the Microbiological Spoilage of Foods and Beverages, Food Microbiology and Food Safety. C Springer Science Business Media, LLC, Pp135-183.

Bello, A.A. (2010). Microorganisms associated with the deterioration of some Citrus fruits. M.Sc. Botany Usmanu Danfodiyo University Sokoto, Nigeria (Unpublished).

Browning, H.W., McGrovern, R.J., Jackson, L.K, Calvet, D.V. and Wardawski, W.F. (1995). Florida Citrus diagnostic guide on citrus and control green and blue moulds of citrus. Biological Control, 8: 81-88.

Chukwuka, K.S., Okonko, I.O. and Adekunle A.A. (2010). Microbial Ecology of Organisms Causing Pawpaw (Carica Papaya L.) Fruit Decay in Oyo State, Nigeria. AmericanEurasian Journal of Toxicological Sciences, 2(1): $43-50$

Citrus commodity notes (2005). Development in international citrus trade in 2004-2005. In: http://www.fao.org/es/esc/en/20953/20990/highl ight 28187ep.html. Retrieved September, $22^{\text {nd }}$ 2012.

Eaton, D.L. and Groopman, J.D. (1994). The toxicology of Aflatoxins, Academic Press, New York, NY; Pp. 383-424.

Eckert, J. and Ogawa, J. (1985). The chemical control of postharvest diseases. Subtropical and tropical fruits Annual Review of Phytopathology, 23: 421-454.

El-Ghaouth, A., Wilson, C.L., Wisniewski, M., Droby, S., Smilanick, J.L. and Korsten, L. (2002). Biological control of postharvest disease of citrus fruits In: Gnanamanickam, S.S. (Ed.) Biological control of crop diseases, Mared Dekker, Inc., New York, Pp. 289-312.

Gorinstein, S., Martin, B.O., Park, Y., Haruenkit, R., Lojek, A., Milan, I., Caspi, A., Libma, I. and Traktenberg, S. (2001). Comparison of some biochemical characteristics of different citrus fruits. Food Chemistry, 74(3) 309-315.

Ifeanyi, A.E. (1995). Fungi associated with the deterioration of Citrus sinensis. B.Sc. Biology Usmanu Danfodiyo University Sokoto, Nigeria (Unpublished).

Ismail, M. and Zhang, J. (2004). Postharvest citrus diseases and their control. Outlook of pest management, 15: 29-35. 
Krogh, P. (1992). Adverse effect of mycotoxins on human health in: seed pathology. In Mathur, S. B. And Jorgensen, J. (Eds), Proceedings of the seminar, 20-25 June 1988, Copenhagen, Denmark, Pp. 149-57.

Miedes, E. and Lorences, E.P. (2004). Apple (Malus domestica) and tomato (lycopersicum) fruits cell-wall hemicelluloses and xyloglucan degradation during penicillium expansum infection. Journal of Agricultural and Food Chemistry, 52: 7957-7963.

Monso, E.M. (2004). Occupational asthma in greenhouse workers, Current Opinion in Pulmonary Medicine, 10: 147-150.

Muhammad, S., Shehu, K. and Amusa, N.A. (2004). Survey of the market diseases and aflatoxin contamination of Tomato (Lycopersicon esculentum MILL) fruits in Sokoto North Western Nigeria. Nutrition and Food Science, 34: Pp.72-76.
Oyeleke, A. and Manga, S.B. (2008). Essential of Laboratory Practice, $3^{\text {rd }}$ edition, Tobest Publishers, Minna, Niger State, Nigeria, Pp.1229.

Prasad, T. (1992). Plant pathogenesis and disease control. Plant Disease Journal of Japan Acado, 56: 367.

Singleton, L.L., Mihail, J.D. and Rush, C.M. (Eds) (1992). Methods for research on soil borne phytopathogenic fungi. APS press, st. paul MN.

Tournas, V.H. and Stack, M.E. (2001). Production of alternariol and alternariol methyl ether by Alternaria alternata grown on fruits at various temperatures. Journal of Food Protection, 64: 528-532.

Tsao, P.H. (1970). Selective Media for Isolation of pathogenic fungi. Annual Review of Phytopathology, 8:157-186. 